The Journal of Laryngology \& Otology

http://journals.cambridge.org/JLO

Additional services for The Journal of Laryngology \& Otology:

Email alerts: $\underline{\text { Click here }}$

Subscriptions: $\underline{\text { Click here }}$

Commercial reprints: $\underline{\text { Click here }}$

Terms of use : $\underline{\text { Click here }}$

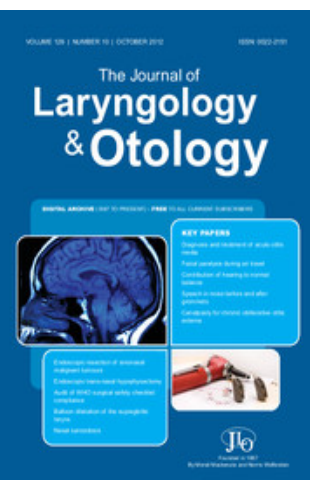

\title{
Audiovestibular manifestations of the antiphospholipid syndrome
}

Tim Vyse, Linda M. Luxon and Mark J. Walport

The Journal of Laryngology \& Otology / Volume 108 / Issue 01 / January 1994, pp 57 - 59

DOI: 10.1017/S0022215100125848, Published online: 29 June 2007

Link to this article: http://journals.cambridge.org/abstract_S0022215100125848

How to cite this article:

Tim Vyse, Linda M. Luxon and Mark J. Walport (1994). Audiovestibular manifestations of the antiphospholipid syndrome.

The Journal of Laryngology \& Otology, 108, pp 57-59 doi:10.1017/S0022215100125848

Request Permissions : $\underline{\text { Click here }}$ 


\title{
Audiovestibular manifestations of the antiphospholipid syndrome
}

\author{
Tim Vyse, Linda M. LuXon*, Mark J. Walport
}

\begin{abstract}
We report on two patients who have high titres of antiphospholipid antibodies, both of whom had acute audiovestibular failure. One of the patients had systemic lupus erythematosus. The other patient had primary antiphospholipid syndrome: audiovestibular symptoms have not been reported in this condition. The occurrence of acute audiovestibular failure in the primary antiphospholipid syndrome raises the question as to whether patients presenting with acute deafness or vestibular disturbance should be screened for the presence of anticardiolipin antibodies.
\end{abstract}

Key words: Lupus erythematosus, systemic; Antibodies, antiphospholipid; Acute audiovestibular failure

\section{Introduction}

Abnormalities of the audiovestibular system have not been documented extensively in patients with systemic lupus erythematosus (SLE), although cranial nerve palsies are well described (Johnson and Richardson, 1968; Feinglass et al., 1976). A significant number of the neuropsychiatric features that occur in SLE have been associated with the presence of circulating antiphospholipid antibodies (Harris et al., 1984); many of these clinical features have also been documented in patients with the primary antiphospholipid syndrome (Mackworth-Young et al., 1989), who do not have sufficient clinical or serological features to fulfil classification criteria for SLE. Antiphospholipid antibodies are associated with a tendency to form intravascular thromboses. This may represent the underlying pathological process accounting for some of the neurological abnormalities that occur in patients with SLE and/or the primary antiphospholipid syndrome (Hart et al., 1984; Lechner and PabingerFashing, 1985). We report two cases of presumed thrombotic damage to the audiovestibular system in patients with antiphospholipid antibodies, an addition to the spectrum of vascular thrombosis associated with the presence of these auto-antibodies.

\section{Case reports}

Case I

A 34-year-old female had a three-month history of malaise and fever and two weeks of episodic dizziness and occasional vertigo and nausea. There was a history of previous photosensitivity but no history of joint pains. On examination she had bilateral cervical lymphadenopathy and bilateral pleural effusions; no neurological abnormality was found. Schirmer's test was normal.

Investigations revealed a normocytic, normochromic anaemia, $\mathrm{Hb} 9.8 \mathrm{~g} / \mathrm{dl}$, total leucocyte count of $8.7 \times 10^{9} / 1$, and thrombocytopenia platelets $87 \times 10^{9} / 1$. The ESR was elevated at $98 \mathrm{~mm}$ in the first hour. There was evidence of renal impairment with a serum creatinine of $150 \mu \mathrm{mol} / \mathrm{l}$, an albumin of $29 \mathrm{~g} / \mathrm{l}$, and creatinine clearance of $43 \mathrm{~mm} / \mathrm{min}$. The $24 \mathrm{~h}$ urinary protein was $1.0 \mathrm{~g}$. Urine microscopy showed granular casts. Immunoglobulin values were: $\operatorname{IgG} 20.1 \mathrm{~g} / \mathrm{l}$; $\operatorname{IgA} 1.85 \mathrm{~g} / \mathrm{l}$; and $\operatorname{IgM}$ $1.20 \mathrm{~g} / \mathrm{l}$. Serological investigations revealed antinuclear antibody (using Hep- 2 cells as substrate) at a low titre of $1: 80$ (speckled); antibody to double-stranded DNA was 10 per cent (normal $<30$ per cent: Farr assay); antibodies to extractable nuclear antigens, Ro and La, were detected by counter-immunoelectrophoresis; latex agglutination for rheumatoid factor was negative; $\mathrm{C} 3, \mathrm{C} 4$ and $\mathrm{CH} 50$ were normal.

Coagulation studies showed normal prothrombin time and activated partial thromboplastin time. No lupus anticoagulant was detected by a dilution phospholipid method (Alving et al., 1985). Circulating anticardiolipin antibodies (ACA) were found by ELISA (Loizou et al., 1985), with an IgG value of 111 ELISA units (normal $<9$ units), and an IgM of $<0.2$ ELISA units (normal $<8$ units). VDRL was negative. Lymph node biopsy showed reactive changes only; bone marrow trephine revealed normal trilineage precursors; renal biopsy showed a diffuse glomerulonephritis without crescents or evidence of significant necrosis.

SLE was diagnosed and the patient was treated with $40 \mathrm{mg}$ of prednisolone. After one year's treatment she was well apart from continuing episodes of visually-induced disorientation and sickness together with vertigo particularly on sudden head movements. Neuro-otological examination showed a total right canal paresis, despite irrigation at $20^{\circ} \mathrm{C}$ for $1 \mathrm{~min}$. There was no significant electronystagmographic finding. Pure tone audiometry, tympanometry, ipsilateral and contralateral stapedial reflex thresholds and brain stem evoked responses were normal. A magnetic resonance image (MRI) of the head was obtained which showed scattered, but small high signal areas within the deep white matter of the cerebrum and a small right-sided middle cerebellar peduncle lesion.

\section{Case 2}

A 23-year-old primigravida presented as an emergency when 27 weeks pregnant with fulminant pre-eclampsia. Initially her blood pressure was $170 / 110 \mathrm{mmHg}$; there was peripheral oedema, and proteinuria ++ on Stix analysis, but no active sedi- 
ment on microscopy. She was restless and there was generalized hyper-reflexia; no other neurological signs were found. Intravenous diazepam and hydralazine were administered. Her blood pressure was readily controlled and she underwent an emergency Caesarean section. A live infant of $750 \mathrm{~g}$ was delivered but he had respiratory difficulties and died one week later. The patient remained confused for the next five days requiring continuing antihypertensives and sedation. She developed thrombocytopenia with a peripheral count of $28 \times 10^{9} / \mathrm{l}, \mathrm{Hb}$ was $10.5 \mathrm{~g} / \mathrm{l}$ and $\mathrm{WBC}$ was $4.3 \times 10^{9} / 1$; a bone marrow trephine showed evidence of bone marrow necrosis. She was managed with regular platelet transfusions until there was spontaneous marrow recovery four weeks later. During this time there was no overt evidence of haemorrhage.

As her mental state improved it became apparent, some three days after presentation, that she was severely deaf and she complained of tinnitus and loss of balance. Her external ocular movements were normal but her gait was broad-based and unsteady. Neither at this time nor previously did she have a history of arthralgia, skin rashes, Raynaud's or alopecia; and there was no antecedent history of migraine. Neuro-otological investigation revealed a total loss of auditory acuity in the left ear and profound loss in the right, but there was an island of hearing at $250 \mathrm{~Hz}$ and $500 \mathrm{~Hz}$. Tympanometry revealed low-normal compliance of the tympanic membranes, but absent stapedial reflexes both ipsilaterally and contralaterally. The caloric responses were absent bilaterally, despite irrigation at $20^{\circ} \mathrm{C}$ for 1 $\min$.

Investigations at the time of presentation showed abnormal blood coagulation: prothrombin time (PT) was $12 \mathrm{~s}$ (control $<13 \mathrm{~s}$ ); partial thromboplastin time (PTTK) $60 \mathrm{~s}$ (normal $<41 \mathrm{~s}$ ), the fibrin degradation products were not elevated. When her audiovestibular symptoms developed they were repeated: PT was $10 \mathrm{~s}$; PTTK was $39 \mathrm{~s}$; and there was a weaklypositive lupus anticoagulant by phospholipid dilution; ACAs were present: IgG was grossly elevated at 300 ELISA units (normal < 9 ELISA units); and IgM 0.9 ELISA units (normal $<8$ ELISA units). In addition she had a false-positive biological test for syphilis: VDRL positive, TPHA and FTA-ABS negative; it is of note that when 12 weeks pregnant she was VDRL negative. Antinuclear antibodies, antibodies to extractable nuclear antigen and rheumatoid factor were not detected. Immunoglobulins were normal.

She was treated with $40 \mathrm{mg}$ of prednisolone. Four weeks later she developed a painful right leg, a femoral vein thrombosis was confirmed by Doppler ultrasonography and she was anticoagulated with warfarin. After five years follow-up there is no improvement in her hearing, but there have been no clinicallyapparent thrombotic events and she remains anticoagulated. Her ACA IgG titre remains very high (between 200 and 300 ELISA units), other lupus serology remains negative.

\section{Discussion}

Circulating antibodies to anionic phospholipids are associated with a clinical syndrome which comprises thrombosis, thrombocytopenia, and recurrent foetal loss (Harris et al., 1985); they may be detected directly, as ACA, by immuno-assay (Harris et al., 1983), or in a proportion of cases as a lupus anticoagulant (LA) (Alving et al., 1985) or using the VDRL reagent. The disease most frequently described in association with $\mathrm{ACA}$ is SLE (Harris et al., 1986). It is not known what proportion of patients with ACA and SLE disease have the primary antiphospholipid syndrome (Mackworth-Young et al., 1989), but it has been shown that some 50 per cent of those with LA do not have an associated condition (Elias and Eldor, 1984). Very high titres of ACA, as was found in the two cases presented, are associated with a greater tendency to thrombosis (Harris et al., 1986).

A broad range of neurological features have been described in association with $\mathrm{ACA}$ and/or LA with a demonstrable vascular aetiology such as stroke, transient ischaemic attack, and multi- infarct dementia (Elias and Eldor, 1984; Harris et al., 1984; Asherson et al., 1987) and vaso-occlusive ocular disease (Asherson et al., 1989). Migraine is also described which may be associated with stroke (Harris et al., 1984). Chorea (Bouchez et al., 1985) and epilepsy (Clauvel et al., 1986) are also reported. These clinical associations encompass both the primary antiphospholipid syndrome and SLE.

The cranial nerve palsies reported in patients with SLE most commonly give rise to facial weakness (VII), extra-ocular muscle paresis (III, IV, VI), or pupillary abnormalities (III); these are not most often seen in conjunction with long tract signs making the brain stem the site of the lesion (Johnson and Richardson, 1968; Feinglass et al., 1976). Involvement of the VIIIth nerve is rare. Examples in the literature are few. Those in which the pathological basis has been demonstrated are: (i) a patient with acute onset of bilateral deafness who then developed coma with a divergent gaze and a fixed dilated right pupil who died after four days. At postmortem she was shown to have had a right intracerebral haemorrhage but also numerous microinfants within the brain stem (Johnson and Richardson, 1968); and (ii) a patient with transient vertigo and diplopia who had a small pontine haemorrhage (Cluxton et al., 1943).

Auditory and vestibular symptoms alone, unassociated with other brain stem symptoms and signs, are unlikely to arise from brain stem ischaemia (Barber and Dionne, 1971). However, it is possible that a vascular lesion of the internal auditory artery is responsible for the audiovestibular features reported. Animal experiments have identified three labyrinthine syndromes consequent upon occlusion of the internal auditory artery: cochlear symptoms alone, vestibular loss or a combination of cochlear and vestibular dysfunction (Kimura and Perlman, 1958). Moreover, labyrinthine artery occlusion with ischaemia of the peripheral labyrinth has been shown to give rise to dizziness and/or hearing loss as shown in a temporal bone study (Gussen, 1976). Auto-immune-related labyrinthine disease has been described although the pathogenesis has not been clearly established. Both cellular and humoral mechanisms have been implicated (Barna and Hughes, 1988). A study of the $\mathrm{C} 3 \mathrm{H} / \mathrm{l} \mathrm{pr}$ murine model of lupus has shown that there is degeneration of the stria vascularis (Trumer et al., 1989). A temporal bone study in three cases of SLE revealed fibrosis and new bone formation in the internal ear (Yoon et al., 1989).

The findings in Case 1 indicate normal cochlear, VIIIth nerve and auditory brain stem function as judged by auditory investigations. The loss of caloric function could be attributed to ischaemia of the vestibular labyrinth extrapolating from earlier animal work, but a recent study (Francis et al., 1992) has shown that rarely a canal paresis may be attributable to a brain stem lesion at the level of the middle cerebellar peduncle. As MRI scanning identified a lesion in this site, and there is no evidence upon auditory investigation of peripheral labyrinthine pathology, it would be reasonable to assume that a small thrombotic brain stem event had given rise to the vestibular abnormalities in Case 1. This would accord well with the brain stem being the primary site of pathology documented in other cranial nerve lesions.

Case 2 presents a more difficult diagnostic problem. The absence of associated neurological signs makes brain stem pathology unlikely. Bilateral total loss of auditory and vestibular function secondary to neurological pathology would require widespread brain stem involvement. The proximity of auditory and vestibular elements within the VIIIth cranial nerve and the peripheral labyrinth would suggest one of these two anatomical sites as the most likely explanation of total auditory and vestibular failure. Although the occurrence of simultaneous bilateral thrombotic events within the audiovestibular system would be surprising, in this case several vascular risk factors were operating and so peripheral labyrinthine ischaemia is the most reasonable explanation for the clinical findings. It is pertinent that in another case of bilateral profound sensorineural hearing loss, sudden deafness in one ear was followed three weeks later 
by profound deafness in the other ear, in a middle-aged woman who was subsequently diagnosed as suffering from SLE (Calderelli et al., 1984). The time course in this case is suggestive of thrombotic events. In addition, bilateral sudden onset of cochleovestibular failure in a young woman was recently reported in a case of polyarteritis nodosa, although no information as to the site of pathology was given (Row-Jones et al., 1990).

ACAs are associated with occlusive vascular disease of the nervous system. We have described two patients with very high titres of these antibodies who suffered acute auditory and vestibular failure. One of these patients also had SLE and ischaemic brain stem events have been documented as the cause of cranial nerve dysfunction in other cases of SLE. MRI scanning confirmed this pathological process in Case 1. The second patient had ACA with no associated connective tissue disease. At the onset of her deafness she was unwell with pre-eclampsia and bone marrow necrosis, however, her blood pressure was controlled and her platelet count maintained above $12 \times 20^{9} / 1$ with no obvious evidence of bleeding. Both are clearly independent vascular risk factors in addition to the ACA. Her condition was compatible with bilateral occlusive vascular disease. The second case raises the possibility that instances of what might be thought of as idiopathic auditory and/or vestibular failure could have a definable vascular aetiology with underlying antiphospholipid antibodies. Although some of the primary cases may give a history of recurrent abortion or venous thrombosis this is not invariable (Mackworth-Young et al., 1989) and hence the condition is only diagnosed if LA, and ACA titres are measured.

\section{References}

Alving, B. M., Baldwin, D. E., Richards, R. L., Jackson, B. L. (1985) The dilute phospholipid activated partial thromboplastin time: a sensitive assay for the verification of lupus anticoagulant. Thrombosis Haemostasis 54: 709-712.

Asherson, R. A., Mercey, D., Phillips, G., Sheehan, N., Gharavi, A E., Harris, E. N., Hughes, G. R. V. (1987) Recurrent stroke and multi-infarct dementia in systemic lupus erythematosus: association with antiphospholipid antibodies. Annals of Rheumatic Diseases 46: 605-611.

Asherson, R. A., Merry, P., Acheson, J. F., Harris, E. N., Hughes, G. R. V. (1989) Antiphospholipid antibodies: a risk factor for occlusive ocular vascular disease in systemic lupus erythematosus and the primary antiphospholipid syndrome. Annals of Rheumatic Diseases 48: 358-361.

Barber, H. O., Dionne, J. (1971) Vestibular findings in vertebrobasilar ischaemia. Annals of Otology 80: 805-812.

Barna, B. P., Hughes, G. B. (1988) Autoimmunity and otologic disease: clinical and experimental aspects. Clinical and Laboratory Medicine 8: 385-398.

Bouchez, B., Arnott, G., Hatron, P. Y. (1985) Chorea and systemic lupus erythematosus with circulating lupus anticoagulant. Three cases. Reviews in Neurology (Paris) 14: 571-577.

Calderelli, D. D., Rejowslei, J. E., Corey, J. P. (1984) Sensorineuronal hearing loss in lupus erythematosus. American Journal of Otology 7: 210-213.

Clauvel, J. P., Tchobroutsky, C., Danon, F., Sultan, Y., Intrator, L., Brouet, J. C. (1986) Spontaneous recurrent fetal wastage and auto-immune abnormalities: a study of 14 cases. Clinical Immunology and Immunopathology 39: 523-530.

Cluxton, H. E., Krause, L. A. M., Smith, W. L. (1943) Acute lupus erythematosus disseminata. Annals of Internal Medicine 19: 843-847.
Elias, M., Eldor, A. (1984) Thromboembolism in patients with the 'lupus'-like circulating anticoagulant. Archives of Internal Medicine 144: 519-525.

Feinglass, E. J., Arnett, F. C., Dorsch, C. A., Zizic, T. M., Stevens, M. B. (1976) Neuropsychiatric manifestations of systemic lupus erythematosus: diagnosis, clinical spectrum, and relationship to other features of the disease. Medicine (Baltimore) 55: 323-339.

Francis, D. A., Bronstein, A. M., Rudge, P., du Bonlay, E. P. G. H. (1992) The site of brain stem lesions causing semicircular canal paresis: an MRI study. Journal of Neurology, Neurosurgery and Psychiatry 55: 446-449.

Gussen, R. (1976) Sudden deafness of vascular origin. A human temporal bone study. Annals of Otology, Rhinology and Laryngology 85: 94-100.

Harris, E. N., Gharavi, A. E., Boey, M. L., Patel, B. M., MackworthYoung, C. G., Loizou, S., Hughes, G. R. V. (1983) Anticardiolipin antibodies: detection by radioimmunoassay and association with thrombosis in systemic lupus erythematosus. Lancet ii: $1211-1214$

Harris, E. N., Gharavi, A. E., Asherson, R. A., Boey, M. L., Hughes, G. R. V. (1984) Cerebral infarction in systemic lupus: association with anticardiolipin antibodies. Clinical and Experimental Rheumatology 2: 47-51.

Harris, E. N., Gharavi, A. E., Hughes, G. R. V. (1985) Anti-phospholipid antibodies. Clinics in Rheumatic Diseases 11: 591-609.

Harris, E. N., Chan, J. K. H., Asherson, R. A., Aber, V. R., Gharavi, A. E., Hughes, G. R. V. (1986) Thrombosis, recurrent fetal loss, and thrombocytopenia: predictive value of the anticardiolipin antibody test. Archives of Internal Medicine 146: 2153-2156.

Hart, R. G., Miller, V. T., Coull, B. M., Bril, V. E. (1984) Cerebral infarction associated with lupus anticoagulant: preliminary report. Stroke 15: 114-118.

Johnson, R. T., Richardson, E. P. (1968) The neurological manifestations of systemic lupus erythematosus: a clinico-pathological study of 24 cases and review of the literature. Medicine (Baltimore) 47: 337-369.

Kimura, M., Perlman, H. B. (1958) Arterial obstruction of the labyrinth. (I) Cochlear changes. (II) Vestibular changes. Annals of Otology, Rhinology and Laryngology 67: 347-365.

Lechner, K., Pabinger-Fashing, I. (1985) Lupus anticoagulants and thrombosis. Haemostasis 15: 254-262.

Loizou, S., McCrea, J. D., Rudge, A. C., Reynolds, R., Boyle, C. C., Harris, E. N. (1985) Measurement of anticardiolipin antibody by an enzyme-linked immunosorbent assay (ELISA): standardization and quantification of results. Clinical and Experimental Immunology 62: 738-745.

Mackworth-Young, C. G., Loizou, S., Walport, M. J. (1989) Primary antiphospholipid syndrome: features of patients with raised anticardiolipin antibodies and no other disorder. Annals of Rheumatic Diseases 48: 362-376.

Row-Jones, J. M., Macallan, D. C., Sorooshian, M. (1990) Polyarteritis nodosa presenting as bilateral sudden onset of cochleovestibular failure in a young woman. Journal of Laryngology and Otology 104: 562-564.

Trumer, D. R., Craven, J. P., Morten, J. I., Mitchel, C. (1989) Autoimmune disease and cochlear pathology in the $\mathrm{C} 3 \mathrm{H} / 1 \mathrm{pr}$ strain mouse. Hearing Research 89: 57-66.

Yoon, T. H., Paparella, M. M., Schachern, P. A. (1989) Systemic vasculitis: a temporal bone histopathologic study. Laryngoscope 99 : $600-609$.

Address for correspondence:

Professor Linda M. Luxon, B.Sc., F.R.C.P.,

Institute of Laryngology and Otology,

Division of Audiological Medicine,

330/332 Gray's Inn Road,

London WCIX 8EE. 